\title{
New Journal Section
}

\section{Distinguished Cytogeneticist}

This is the first contribution to a new section in which the journal proudly highlights the contributions of individual scientists to cytogenetics. The aim of the section is not only to recognise and applaud their achievements, but also to provide a historical context around some of the most important developments and discoveries in cytogenetics.

The format of the following contribution and those to come is the following: Individual scientists are invited to select and submit a list of 50 of their most important or favourite publications and a CV. The section comprises a commentary introducing the scientists concerned, summarises the significance of their achievements, and combines this with the curriculum vitae and the selected publication list.

The editorial board hopes that this section will be of interest to all readers, but in particular will help those younger colleagues, who were not around at the time the events took place, to understand how our fascinating field of science has reached its current state.

Both readers and members of the editorial board are welcome to nominate candidates for the Distinguished Cytogeneticists Section. Final selection will be performed by the editorial board.

Michael Schmid 